\title{
"Alguém a fim?": \\ uma etnografia on-line em salas de bate-papo na Fronteira Brasil-Bolívia
}

\section{Carla Cristina de Souza}

Universidade Federal de Mato Grosso do Sul | Campo Grande, MS, Brasil carlinhacdsouza@gmail.com | https://orcid.org/0000-0002-6948-642X

\section{Tiago Duque}

Universidade Federal de Mato Crosso do Sul | Campo Grande, MS, Brasil tiago.duque@ufms.br|https://orcid.org/0000-0003-1831-0915
O presente artigo apresenta parte dos resultados de uma pesquisa sobre gênero, sexualidade e diferenças, em uma perspectiva socioantropológica, na área de fronteira Brasil-Bolívia. Ele busca analisar experiências de interações de usuários/as das salas de bate-papo do provedor Universo Online (UOL) Corumbá. A metodologia é, principalmente, a etnografia on-line, mas também apresenta parte do trabalho de campo off-line realizado nessa região fronteiriça em Mato Grosso do Sul. A perspectiva teórica é pós-estruturalista, em especial, estudos subalternos (queer, feminista, pós-colonial). O enfoque é para as relações de gêneros dissidentes e sexualidades disparatadas nesse ambiente virtual, sem, contudo, deixar de compreendê-lo a partir do contexto off-line. As reflexões apontam para o erotismo presente nesse espaço virtual, assim como discute a experiência da produção de um "Outro" desvalorizado. Busca, ainda, contribuir para as reflexões no campo metodológico das pesquisas em ambientes da internet e em regiões de fronteira.

\footnotetext{
“Alguém a fim?": an On-line Ethnography in Chat Rooms in the Brazil-Bolivia Border
}

\footnotetext{
ABSTRACT The present article presents part of the results of a research on gender, sexuality and differences, from a socio-anthropological perspective, in the Brazil-Bolivia border area. It seeks to analyze experiences of users' interactions in the chat rooms Uol Corumbá. The methodology is mainly on-line ethnography, but also presents part of the offline field work done in this border region in Mato Grosso do Sul. The theoretical perspective is poststructuralist, especially subaltern studies (queer, feminist, postcolonial). The focus is on the relationships of dissenting genders and disparate sexualities in this virtual environment, without, however, failing to understand it from the offline context. The reflections point to the eroticism present in this virtual space, as well as discusses the experience of the production of a devalued "Other". It also seeks to contribute to the reflections in the methodological field of research in Internet environments and in border regions.
}

DOI

http://dx.doi.org/10.11606/ 2179-0892.ra.2020.170814
Cênero,

Sexualidade, Etnografia Online, Fronteira, Redes Sociais.
KEYWORDS

Gender, Sexuality, On-line Ethnography, Border, Social Networks. 


\section{INTRODUÇÃO}

O presente artigo é fruto, principalmente, de uma etnografia on-line na sala de bate-papo Uol Corumbá, que buscou analisar as interações dos usuários e usuárias no que se refere a gênero e sexualidade na área de fronteira Brasil-Bolívia. Ele também apresenta dados obtidos durante o campo etnográfico off-line da pesquisa "Cênero, Sexualidade e diferenças: normas e convenções sociais na fronteira Brasil-Bolívia"1, iniciada em 2014 e finalizada em 2019.

Considerando o recente cenário político brasileiro, em que pesquisadores/ as das Ciências Humanas, sobretudo os/as que produzem conhecimentos sobre as relações humanas em suas intersecções com gênero e sexualidade, estão sendo atacadas/os e deslegitimadas/os, torna-se um ato político e de resistência demarcar que o que produzimos não é "ideologia", ou mera opinião a respeito de um contexto/ realidade e experiências dos sujeitos. Diante desses ataques,

\footnotetext{
É preciso que encontremos um ponto de equilíbrio entre, de um lado, a afirmação de que o conhecimento que produzimos é necessariamente situado - política e epistemologicamente -e, portanto, jamais 'neutro'; e, de outro, a defesa da autonomia (relativa por certo) do campo científico e das convenções que o regem. (Carrara, França e Simões, 2018: 75).
}

Nesse sentido demarcamos o campo teórico e metodológico fundamentados cientificamente por meio de leituras e reflexões de outras produções dentro de uma perspectiva que tece críticas a universalidade e essencialidade do gênero e sexualidade. Assim, as experiências de gêneros dissidentes são aquelas que não correspondem à chamada matriz da inteligibilidade de gênero (Butler, 2003). Ela se estrutura de uma forma que aquela e aquele que não se adequa, é considerado como dissidente, um estranho; ou seja, a matriz produz quem são os "normais" e os que não são, de acordo com as possibilidades restritas de relações nela apresentada, isto é, as de "sexo" masculino = gênero masculino = desejo pelo "sexo oposto" ou "sexo" feminino = gênero feminino = desejo pelo "sexo oposto". O não cumprimento dessa matriz em relação ao desejo por alguém do "sexo oposto", que escapa a certos controles disciplinares dos prazeres, produz uma espécie de sexualidade disparatada (Foucault, 2007).

No entanto, cabe-nos atentar para a dinamicidade do que é ser de gênero dissidente e/ou sexualidade disparatada. Para isso, devemos ter claro que a experiência corporal é uma das dimensões para a produção ou não dessa "rebeldia". Isso significa que, mesmo tendo identificação oposta à qual a pessoa foi classificada ao nascer, inclusive com vivência à sexualidade fora das expectativas, há casos/situações em que a dissidência é invisibilizada pois o sujeito performatiza uma identidade de acordo com as expectativas mais conservadoras em termos de gênero e sexualidade ou, até mesmo, não revela tal diferenciação. Contudo, a "rebeldia" não exclusivamente se
1) O presente trabalho teve apoio da Universidade Federal de Mato Grosso do Sul, da Coordenação de Aperfeiçoamento de Pessoal de Nível Superior-Brasil (CAPES) - Código de Financiamento 001 e do Programa Institucional de Bolsas de Iniciação Científica (PIBIC), financiado pelo Conselho Nacional de Desenvolvimento Científico e Tecnológico (CNPq)

2 | Utilizamos "sexo" entre aspas no sentido de problematizar qualquer possibilidade de compreensão biologicista/essencialista desta categoria, isto é, aqui "sexo" é uma regulamentação sociocultural, não é tomado como natural/natureza. 
expressa nas experiências corpóreas, "a consciência política e a agência transformadora não são determinadas pelas estruturas biológicas, por experiência localizável exclusivamente no corpo" (Bento, 2011:105), sendo os discursos subversivos também produtores dessas dissidências.

A metodologia usada nesse artigo foi, principalmente, a etnografia on-line durante quatro meses (de agosto a outubro de 2015), na sala de bate-papo UOL Corumbá, e a etnografia off-line durante um prazo maior (de abril de 2015 a dezembro de 2017), em diferentes contextos na região de fronteira Brasil-Bolívia, no estado de Mato Grosso do Sul. A partir dos fragmentos de conversas on-line "públicas"3 e mensagens "reservadamente"4 destinadas para a autora deste estudo, buscou-se compreender como são as relações de sociabilidade de usuários/as nesse bate-papo, sem, contudo, deixar de compreendê-lo a partir do contexto off-line.

Pelo fato de a maior parte dos usuários/as da sala de bate-papo UOL Corumbá estar em busca de encontros off-line (fora do ambiente virtual), entende-se que seus frequentadores/as possivelmente morem na região caracterizada pelo título da sala (já que isso facilitaria o encontro). Nesse sentido, é muito provável que residam nas cidades bolivianas Puerto Quijarro e Puerto Suárez, ou nas brasileiras Corumbá e Ladário, ou que sejam turistas visitando ou de passagem pela região e que estejam à procura de encontros.

Dentre essas cidades, Corumbá é a maior. Teve como estimativa 108.899 habitantes em $2017^{5}$. Ela está à margem direita do Rio Paraguai. É conhecida, especialmente, pelo turismo de pesca nos rios pantaneiros. Além disso, em relação a essa cidade, podemos afirmar que

É um território de configuração estratégica por ser o principal ponto de contato entre o Brasil e a Bolívia. Por ali passa o gasoduto e um amontoado de mercadorias outras (chegam ou partem) utilizando o rio, as rodovias e as ferrovias que se aproximam (Oliveira \& Esselin, 2015: 127).

Esse contexto econômico é apenas um fragmento da relação fronteiriça Brasil/ Bolívia, afinal, "a multiplicidade e riqueza do cenário sociocultural pantaneiro é tal que abriga povos com línguas diferentes, com histórias e atividades econômicas próprios, com costumes particulares que os distinguem no contexto da planície" (Banducci Junior, 2012: 21). Porém, não diferente do que comumente é, as relações de sociabilidades interculturais (neste caso Brasil/Bolívia), mesmo quando recíprocas, hora ou outra também causam "estranhamentos", e como discutiremos no decorrer deste artigo, criam os "outros" em posições de hierarquias.

Por sua vez, o ambiente on-line, que compõe esta etnografia, também foi tomado aqui como uma plataforma incorporada neste fluxo de sociabilidades que não está restrito aos limites técnicos do programa, site ou aplicativo. Dito de outro modo, "dentro de uma mesma plataforma, por exemplo, são identificados diferentes ambientes, pois
3| Quando o usuário opta po teclar "publicamente", isto é, no modo "público", é porque a mensagem digitada a um usuário poderá ser vista por todos. Há ainda a opção de enviar mensagens a "todos" os presentes na sala, o que torna a mensagem também "pública".

4 | Quando o usuário opta por conversar com outro "reservadamente", isto é, no modo "reservado", diferentemente do que foi dito na nota anterior, é porque não quer que mais ninguém que esteja na sala visualize a conversa.

5| Dado do IBCE, Diretoria de Pesquisas, Coordenação de População e Indicadores Sociais, Estimativas da população residente com data de referência $1^{\circ}$ de julho de 2017. 
não existem apenas por suas características em termos de software ou hardware, mas pelas diferentes formas de serem habitados" (Leitão, Comes, 2017: 62). Nesse sentido, os envoltos das relações interculturais, através das trocas, enunciados, comentários e das diversas outras formas de interações, também podem ser percebidos nesses ambientes virtuais, já que se conectam em um continuum com os espaços off-line.

De modo geral, Magnani (2002) percebeu que as "cidades globais" estão produzindo novas formas de comunicação, uma característica da modernização. Elas são entendidas por diferentes autores como sendo aquelas que possuem rede de hotéis de padrão internacional, sistema de transportes seletivo, além de empresas de informação de ponta e agências de serviços especializados.

Mas, através de Corumbá, vemos que não são somente as "cidades globais" que têm esses tipos de produções, inclusive das relações via espaço on-line. Assim, mesmo cidades "pequenas", quando comparadas às "globais", também não têm nas tecnologias uma forma de enfraquecimento. Como aponta Magnani (2002) em relação às cidades maiores, podemos afirmar em relação ao nosso contexto de estudo: a comunicação/interação on-line é um facilitador para as interações nas cidades e, inclusive, neste artigo podemos mostrar que, para quem quer marcar encontros, conhecer pessoas e procurar por sexo de forma mais "discreta", as tecnologias digitais é uma opção facilitadora de interação na cidade.

\section{A ETNOGRAFIA ON-LINE: REFLEXÕES TEÓRICO-METODOLÓGICAS}

Com o aumento da adesão ao uso da internet e a expansão da sociabilidade vias mídias digitais, surgiram novos meios de se fazer etnografia, o que alguns pesquisadores e pesquisadoras chamaram de "netnografia". Ela "nasce em função da necessidade da academia de abordar um 'novo' espaço, o virtual, o online" (Noveli, 2010: 109). Surge como uma etnografia especializada, adaptada às contingências específicas dos mundos sociais de hoje, mediadas por computadores (Kozinetz, 2010). Etnografia virtual também é um dos termos utilizados nesse campo metodológico. O que diferencia os usos dos diferentes termos é a questão disciplinar das áreas de produção do conhecimento.

\footnotetext{
O termo netnografia tem sido mais amplamente utilizado pelos pesquisadores da área do marketing e da administração enquanto o termo etnografia virtual é mais utilizado pelos pesquisadores da área da antropologia e das ciências sociais (Amaral, Natal, Viana et al., 2008: 34).
}

Aqui, como estamos empenhados em demarcar que on-line e off-line não estão em mundos separados, e realizamos observações e interações nestes dois ambientes, utilizaremos etnografia on-line e off-line para nos referirmos a essas práticas metodológicas, entendendo que as experiências on-line são uma continuidade da vida off-line: 


\footnotetext{
"on-line" ou "virtual", não é um espaço destacado do mundo "off-line" ou "real"; estas classificações não devem ser pensadas como absolutas, nem formam uma dicotomia. Não são planos radicalmente apartados, mas contextos que se interpenetram e se influenciam mutuamente. $A$ internet não forma um espaço autônomo, que existe em paralelo aos espaços físicos; a distinção on-line/ off-line é circunstancial e precária, "real" e "virtual" estão constantemente articulados. A rede é parte do mundo, e não um “mundo à parte (Braga, 2015: 228).
}

Dito de outro modo, em relação às observações e interações on-line, conforme Miller (2013), reconhecemos a tecnologia da internet como um gênero cultural, e como tal, não nos permite criar algo radicalmente novo, mas antes realizar um desejo já presente anteriormente, que porém não tinha como ser realizado, visto que faltavam os meios. Mas pode haver uma consequência no seu uso, que é a possibilidade de explorar novas coisas, experimentar novas liberdades, "mas isso também induz ansiedades quanto ao controle sobre como essas liberdades e capacidades serão empregadas" (Idem: 173).

Ainda sobre esse ambiente, a visão sobre o virtual, dentro de algumas perspectivas, apresenta-se como um espaço onde há a possibilidade de um sujeito poder estar/entrar criando e se identificando com "um corpo", isto é, um avatar. Na referida sala é comum muitos/as usuários/as descreverem seus corpos e características físicas, independentemente de serem solicitados a fazerem-no. Cria-se então a "identidade virtual", uma vez que "a identificação dentro da rede ganhou uma relativa autonomia frente à identidade fora da rede e tornou-se a base para a construção de uma identidade virtual" (Ramos, 2015: 65).

Porém, ainda que essa identidade possa vir a ser considerada algo fictício, e as ações nestes ambientes sejam alheias às práticas que sujeitos têm da vida "real", não podemos desconsiderar o que Ramos (2015) chamou de "convergência identitária", a agência dessas pessoas ao elaborar/construir/ser esse avatar virtual, este "outro sujeito" imaginário, pois vemos que este "outro" ainda faz parte da constituição identitária, ainda que não verbalizada/performatizada no off-line. Nesse sentido, a agência diz respeito às "possibilidades no que se refere à capacidade de agir, mediada cultural e socialmente" (Piscitelli, 2008: 267). Ou ainda, como bem afirmou Beleli (2015), a criação dos perfis não pode ser pensada como o afastamento de uma "realidade", mas na qualidade de uma manipulação estratégica de si.

Sobre esta afirmação, vemos por outro ponto, a de que não há atriz/ator interpretando, investindo em avatares, criando papéis, pois mesmo que estes sejam escolhidos aleatoriamente com pré-caracteres disponíveis pela plataforma on-line, há processos de escolhas subjetivas de pessoas reais, que interagem, através desses "outros corpos", com outras também reais, no contexto fronteiriço em questão. Isso faz com que seja legítima a compreensão desse ambiente como uma 
continuidade de lugares off-line, e não uma invenção, um mundo à parte, como já apontado anteriormente.

Com os avanços da tecnologia, que com suas novas ferramentas de comunicação, como a internet, permite o contato entre pessoas de variados lugares do mundo, em diferentes contextos e temporalidade como o nosso, é quase indispensável fazer uma pesquisa hoje sem levar em consideração as relações sociais que as pessoas estabelecem nas mídias digitais.

\footnotetext{
Nas ciências sociais, nossos olhares costumam se voltar para as relações entre as pessoas e delas com a sociedade. Se agora essas relações se iniciam, são expandidas ou mantidas pelo uso de mídias digitais precisamos começar a reconhecer seu papel na experiência de nossos sujeitos tanto em termos sociais quanto subjetivos (Miskolci, 2011: 13).
}

Logo, o uso da internet, especialmente a sociabilidade via redes sociais, nos possibilita conectar e interagir com os sujeitos, contribuindo para um alcance de qualquer lado da fronteira Brasil-Bolívia, sem necessariamente cruzá-la geograficamente. Além disso, nos permite ter mais facilmente um contato com os interlocutores e interlocutoras quando estes apresentam a necessidade de permanecer no anonimato, ou mesmo uma resistência de um encontro off-line. Contudo, essas novas técnicas nos trazem questionamentos bastante pertinentes do ponto de vista ético, assim com as vantagens e desvantagens em relação ao que ela nos permite conhecer em campo.

Nesse sentido, como escolha metodológica, a pesquisadora, durante todo o campo, conteve-se em somente observar o que era postado publicamente na sala através das conversas, e não se comunicou com os usuários, embora houvessem pessoas, majoritariamente, com nickname no masculino, tentando se comunicar com ela. Por sua vez, a presença dela na sala já configurava certa intervenção no ambiente on-line, afinal, os seus diferentes apelidos/nicknames que foram usados em campo eram, em si mesmos, uma forma de interação naquele espaço. Como ficará demonstrado mais a frente, isso já nos forneceu muitas informações a respeito dos tipos de relações que os usuários da sala buscavam. Mas, aqui, nos cabe questionar: sem a identificação enquanto pesquisadora, os dados levantados são possíveis, em uma perspectiva ética, de serem trabalhados neste estudo?

Reforçamos que não foram feitas entrevistas com as pessoas da sala, nem mesmo as tentativas de diálogo com a pesquisadora, em seus diversos momentos e nicknames foram retribuídas. Entendemos que se trata de uma observação participante porque ela estava inserida naquele meio, e as pessoas a "viam" e buscavam interação. De maneira ainda provisória, imaginamos que a sala pudesse ser como uma praça pública. Muitas pessoas que passam, permanecendo ou não na praça a vê, mas não se estabelece qualquer tipo de diálogo, ainda que a forma como a pesquisadora 
se apresenta, assim como os demais, componha a cena.

Há diversos interesses das pessoas que passam ou estão em uma praça, como o que ocorre com a sala on-line, ainda que o nosso foco seja um tema específico. A pesquisadora, nessa imagem pública e off-line hipotética, não se apresenta às pessoas da praça como pesquisadora, ainda que esteja etnografando as relações que ali se dão. Ela sequer cumprimenta quem educadamente tenta uma aproximação, mas interfere por estar ali: é mais uma pessoa que frequenta o ambiente.

Logo, considerando essa comparação provisória, da sala de bate-papo como uma praça off-line pública imaginada, pensamos que não haveria problemas éticos em etnografar a sala on-line, sem que a autora desse estudo se identificasse como pesquisadora. Em um estudo anterior, um dos autores desse artigo, etnografou uma praça com as características que aqui foram apresentadas para a associação com o ambiente on-line. O trabalho de campo anterior, na praça, não apenas tornou possível a caracterização que fizemos aqui de forma suscinta, como a própria experiência de estar em meio a muita gente, mas não necessariamente manter algum tipo de diálogo, ou, inclusive, entender que não deveria gritar em praça pública que era um pesquisador e estava ali desenvolvendo um estudo e que, por isso, pedia a autorização de todos os transeuntes (Duque, 2011).

Feitas essas considerações, descreveremos a sala de bate-papo Uol. Ela é um espaço de sociabilidade on-line onde pessoas de diferentes lugares do mundo conseguem se comunicar umas com as outras. As salas são divididas por "Amizade", "Idades", "Namoro", "Papo Sério", "Sexo", "Cidades e Regiões" e "Criadas por assinantes", e subdivididas. Por exemplo, a sala "Amizade", possui as subdivisões "Amizade Virtual", "Amizade colorida", "Amizade LCBT" e "Desabafo". Cada opção dessas contém 35 outras salas numeradas para serem escolhidas, com possibilidade de um número restrito de usuários/as assinantes e não assinantes por sala ${ }^{6}$.

A sala de bate-papo Uol "Cidades e Regiões" possui uma variedade de cidades disponíveis de diversos estados do Brasil, além de contar com duas salas para é referente ao período em que ocorreu o campo, já descrito neste artigo. "Brasileiros no exterior" e "Estrangeiros no Brasil". Dentre essa diversidade de salas disponíveis para variedades de intenções, focamos nas salas "Cidades e Regiões", onde está alocada a sala Uol Corumbá. O número de salas por cidade varia: no caso de Corumbá, no momento da etnografia on-line eram três, mas conforme nossas observações e acessos, sempre encontramos pessoas em apenas uma das salas, pois as demais não tinham usuários/as nos dias e horários que as acessamos. Depois do término do trabalho de campo on-line, quando da finalização deste texto, percebemos que ocorreram mudanças nas salas Uol, fazendo com que, por exemplo, Corumbá ficasse apenas com uma sala disponível.

O bate-papo UOL, principalmente quando se refere às salas locais, como os agrupamentos de sala por cidades, como é o caso das salas de Corumbá, pode ser considerado um facilitador para se marcar encontros off-line na cidade. Isso 
ficou perceptível desde o primeiro momento de imersão no campo, quando foi possível observar as conversas "públicas" dentro da sala, isto é, as que os usuários/as não restringiam ao "privado" (entre duas pessoas apenas). Ou, ainda, quando, mesmo tendo escolhido "privado", mandavam as mensagens a "todos" os membros da sala, opção que favorecia a pesquisadora, como qualquer outra pessoa da sala, também recebê-las. A dinâmica de interações observadas na sala será discutida a seguir.

\section{AS INTENÇõES VIA NICKNAMES: EXPERIÊNCIAS DE (IN)VISIBILIDADES}

Quando os/as usuários/as entram nas salas, eles/as digitam um apelido, correspondente a um nome, nickname (nick), que as outras pessoas terão como referência naquele ambiente. Nas salas, desde as primeiras incursões, ao atentar para os apelidos percebe-se o quanto o espaço é erotizado. Vejamos o caso das siglas "PC" e "\$". Seus significados variam de acordo com outras características do apelido ou a própria conversa em público.

Algumas impressões que tivemos de início foi achar que as letras "PC" pudessem se referir a um "Pau Grande", mas compreendemos, com o caminhar do trabalho de campo, que se tratava de uma referência a usuários/as que faziam programa ("PC" = Programa). Citamos dois exemplos: "Menprograma.32 fala para Todos: PG só com mulheres". (Segunda-feira, 12/10/2015, horário de entrada na sala às 15:11) e "boy d pg hxh (reservadamente) fala para Todos: alguém afim só branco altura 174 kg64 eu tenho 21 anos eu sou discreto eu faço programa ser alguém tiver afim só chamar". (Quinta-feira, 27/08/2015, horário de entrada na sala às 20:52). Já o cifrão (“\$”), que é uma das representações do dinheiro, destaca a oferta ou busca por serviços sexuais, sexo com outro homem". por exemplo: “\$morena”.

Outros nicks, sem o uso desses códigos, também são acessados via interações com intenção de sexo/encontro mediado por dinheiro, como no caso em que um usuário chamado "Jorge" disse a "Carolzinha": "quer sair pra fazer sexo? Qto cobra?". (Quinta-feira, 24/09/2015, horário de entrada na sala às 09:23). Ou quando "PACOMenina\$sigilo" disse a "Lukinhas": "oi quants anos?" (Sexta-feira, 25/09/2015, horário de entrada na sala às 10:45).

Há ainda a publicidade referente ao site "acompanhantesms.com.br" e a venda de produtos eróticos, por exemplo: "Loyra23 fala para DELECADO: \#\# Chega de ejaculação precoce! Faça sexo o tempo que quiser! Conheça nosso CEL $\Rightarrow$ www. gelmaisXXX" (Domingo, 01/11/2015, horário de entrada na sala às 16:46).

A partir dessa observação inicial, foram feitos os testes de entrar na sala usando diferentes nicknames, entre eles: "Aninha", "Carolzinha", "Carlão", "Flor", "Leandrinho", "Marcão", "Laura”, "Lukinhas", "Carlos" e "Zeus". Esses primeiros testes, propositalmente, foram com nicks que não pudessem revelar o tipo de relacionamento 
afetivo-sexual que supostamente se procurava. Com cada um deles, permaneceu-se na sala por aproximadamente uma hora, em distintos dias e horários da semana.

Foi possível perceber que o maior número de usuários com nicks masculinos entrava em contato com a pesquisadora quando usava apelidos no feminino e diminutivo, como quando usou-se "Carolzinha", o que não ocorreu quando foi usado "Laura" e "Flor". Uma característica também observada foi que "Carolzinha" era comumente acessada por nicks masculinos no modo "reservado" mais frequentemente do que os outros apelidos femininos que não no diminutivo.

Isso fica evidente quando os dados do campo apresentam que, dos trinta e três ocupantes na sala de bate-papo Uol, no momento da entrada da pesquisadora usando o nickname de "Carolzinha", vinte e seis usuários entraram em contato com ela, sendo vinte e cinco desses usuários com os apelidos descritos no masculino e apenas uma descrita no feminino. Em outro momento, entrando com o mesmo nickname em horário diferente, dos trinta e nove ocupantes da sala, trinta e dois deles entraram em contato com a pesquisadora, sendo trinta desses com os nicks no masculino.

No caso do nickname "Laura", que não estava no diminutivo, de trinta e sete usuários, dezenove vieram falar com a pesquisadora, sendo dezesseis usuários no masculino, uma usuária no feminino e dois que expressavam ser de gênero dissidentes e/ou sexualidades disparatadas. Uma interpretação possível é a de que o marcador da diferença que expressava a geração era muito acessado por usuários homens, que com muita frequência buscaram conversar com uma mulher que se descrevia como mais jovem.

Dos nicknames utilizados pela pesquisadora no masculino, o mais acessado também foi o que ela colocou no diminutivo, no caso, "Leandrinho". O campo mostrou que dos dezesseis usuários de gênero dissidentes e/ou sexualidades disparatadas (com nicks no masculino), oito vieram entrar em contato com a pesquisadora enquanto usava o nick "Leandrinho", e apenas uma usuária no feminino, de todos os trinta e um ocupantes da sala. Diferente do nick "Carlos", que dos trinta e oito ocupantes da sala, apenas três entraram em contato, sendo duas com "apelidos" no feminino, e um deles que expressava ser do gênero dissidente e/ou sexualidade disparatada. No campo apresentou ser recorrente a procura por usuários/as que expressam o marcador social geracional da juventude, ainda mais quando este se articulava com o gênero feminino.

Segundo regras do bate-papo Uol, usuários menores de 18 anos não podem frequentar as salas, por isso, entre as salas que estão agrupadas por idade, a menor faixa etária disponível é a de 18 a 20 anos. No entanto, a ferramenta tecnológica e virtual não incapacita uma pessoa menor de idade a entrar em alguma das salas disponíveis. Neste caso, não é possível saber ao certo como "Carolzinha" poderia ser compreendida, se seria uma mulher jovem ou simplesmente uma mulher pequena/baixa, ainda que mais velha. No entanto, ao conviver na sala, avaliamos que a 
probabilidade do diminutivo nos nicks estar relacionado pelos usuários homens a estatura isoladamente, desassociada da baixa idade, seria bem menor.

Em um outro momento, foram testados apelidos mais descritivos em relação a práticas afetivo-sexuais e performances de gênero: "ATVO.MADURO", "H Ativo", "Pass Discreto"10, "Passivinho"11, "Afeminado qr Macho"12, "Gay quer dar"13 e "Quero Ativo"14. São nicks com esse perfil que aqui nos referimos como sendo indicadores de gêneros dissidentes e sexualidades disparatadas. Na sala há muitos usuários/as que, pelo apelido, conseguimos interpretar o que buscam, em especial, no que se refere a gêneros dissidentes e/ou sexualidades disparatadas. Há ainda a possibilidade de, diferentemente do que se comunica com os nicks, perceber isso pela observação dos diálogos "públicos" ou "privados".

Um exemplo disso é quando o usuário "SEXOJA" não descreve em seu apelido sua orientação sexual e o que deseja em termos de prática sexual, mas compreendemos que se trata de um "HSH" quando através do contato via mensagem "reservada" para o nick"Lukinhas", que essa pesquisadora usava, ele disse: "sou gay passivo vccurte comer um cuzinho?” (Domingo, dia 04/10/2015, horário de entrada na sala às 17:39). 0 mesmo ocorreu, por exemplo, quando se usou o nick "H Ativo". Nessa situação, os usuários que acessaram a pesquisadora foram "Ryan 27", "Cabriel”, "Brancão", "Raphael”. Todos com nicks que, antes de fazer contato com "H Ativo", passaram despercebidos enquanto pessoas com gêneros dissidentes e/ou sexualidades disparatadas.

Outro exemplo foi quando "H Sarado" perguntou a essa pesquisadora que estava na sala como "ATVO. MADURO": "apenas ativo?" (Segunda-feira, 26/10/2015, horário de entrada na sala às 19:18). Também teve o "Grisalho Karinho", que perguntou a "Afeminado qr macho": "olá, quer um marido?" (Domingo, 01/11/2015, horário de entrada na sala às 14:52). Todos são usuários que apenas em diálogo com o "apelido" que a pesquisadora usava, poderia ser identificado ou não como um ocupante da sala em busca de práticas homoeróticas. O campo mostrou que quando a pesquisadora entrou com os nicknames no masculino e os apresentados acima que expressam uma expectativa ligada a homoafetividade, o maior número de interesse/procura era expressivamente de usuários que se apelidavam no masculino.

Esses nicknames apresentam, em alguns momentos, uma dinâmica de interação que Braga (2015) apontou como sendo um dos modelos normativos coexistente de parceria homoerótica, por ter uma aproximação da prática heterossexual tradicional, em que pares passivo/feminino e ativo/masculino são associados, ou seja, a masculinidade de um depende da feminização do outro. Além disso, nessa questão erótica, os homens que se identificam ou são lidos como sendo efeminados, tendem a ser menos valorizados.

Isso também ocorreu no trabalho etnográfico off-line deste pesquisador, que ouviu de um dos interlocutores homens que se recusava a manter relacionamento com homens efeminados nos ambientes off-line e on-line; que a "discrição" nos
8| "Ativo" é um homem que, na relação sexual anal com outro homem, prefere penetrar o parceiro. "Maduro" é um usuário mais velho.

9| "H" é o mesmo que homem.

10| "Pass" é um homem que na relação sexual anal com outro homem, prefere ser penetrado pelo parceiro. "Discreto" é um homem que não é efeminado ou que não aparenta ser gay.

11 "Passivinho" é um homem jovem, ou pequeno, que na relação sexual anal com outro homem, prefere ser penetrado pelo parceiro.

12 | "Afeminado" é um homem com voz, trejeitos e/ou roupas tidas como femininas. "qr" é a abreviatura, na linguagem da internet, de "quero", isto é, "busco" ou "desejo". "Macho" é um homem viril, masculino, que se identifica como heterossexual.

13 "Cay quer dar" é um homem gay que deseja se passivo na relação sexual anal com o parceiro.

14 | "Quero Ativo" é um homem que deseja um outro homem que, na relação sexual anal, prefira penetrar o parceiro. 
espaços públicos fora da internet também tinha que se fazer presente no ambiente on-line, especialmente quando da escolha do apelido no chat. Disse ele: "Você não pode escolher um nome muito chamativo, que dêa entender que você curte homens ou seja gay. É preciso escolher um nome normal de homem, como André, Paulo, João, se você quiser encontrar sexo com homens discretos na internet" (anotações do caderno de campo). Assim,

\footnotetext{
$\mathrm{Na}$ era dos desejos digitais, as imagens nas telas mediam buscas para encontros face a face. Ainda que driblem tecnologicamente o impedimento da expressão do interesse sexual por pessoas do mesmo sexo, o fazem dentro de termos que permitem o encontro off-line com segurança, o que, no caso entre homens, demanda que sejam 'discretos'. Dessa forma, por mais que se expresse on-line, onde permanecem sob condições desiguais e discriminatórias. (Miskolci, 2017: 286).
}

Portanto, a etnografia on-line na sala de bate-papo Uol Corumbá não nos permite afirmar que pode ser mais fácil ser abordado por um determinado perfil desejado de usuário quando utiliza-se uma descrição no apelido que já informa a preferência sexual e o interesse na busca por parceiros/as, do que usar um nick genérico, "um nome normal de homem", por exemplo. Ou seja, a interação é mais complexa do que parece. Essas diversas tramas do desejo e da busca on-line, contudo, não abalam a praticidade e objetividade nas interações com interesse afetivo-sexual. "Mas, provavelmente, o maior atrativo reside na possibilidade de entreter 'paqueras' múltiplas e simultâneas ampliando suas probabilidades de encontrar alguém sem se expor da mesma forma que na vida off-line" (Miskolci, 2012: 4).

Considerando isso, algumas salas de bate-papo Uol são voltadas para relacionamentos entre pessoas classificadas como do mesmo sexo, como as salas "Amizade GLS"5", "Namoro GLS", "Gays e afins" e "GLS por localidade". As salas "GLS" estão separadas por "Bissexuais", "Crossdressers", "Gays", "Lésbicas", "Transexuais" e "Travestis". Mas, como se viu com a análise dos dados aqui apresentados, a existência dessas salas "específicas" não é um impedimento para esses usuários entrarem e interagirem em salas locais como as de Corumbá, até porque as salas locais, como dito anteriormente, são facilitadoras para se marcar encontros off-line. Sobre a possibilidade de encontros, especialmente com homens bolivianos, moradores do outro lado da fronteira, discutiremos a seguir.

\section{CORUMBÁ ON-LINE E OFF-LINE: ESPAÇO DE (DES)ENCONTROS (TRANS)FRONTEIRIÇOS}

Há uma característica fronteiriça da região que merece destaque por ter especial implicação no que se refere ao tema desse artigo. 
A fronteira em seu sentido mais comum está ligada ao preconceito por sua condição de margem, portanto, marginal a uma noção, decorrente de questões históricas e políticas. É um local no qual se pode assimilar a negatividade, atribuída por diversos fatores como o ilícito, a clandestinidade, a miscigenação, entre outros. (Oliveira e Campos, 2012: 17).

Por isso, partindo desta "imagem negativa do senso comum" construída a partir da "condição de margem" que pensamos ser importante problematizar a avaliação de que Corumbá não é uma cidade preconceituosa em relação às experiências de gêneros dissidentes e sexualidades disparatadas, diferente do lado boliviano, segundo a lógica local bastante difundida. Uma frase recorrente no trabal ho etnográfico off-line de interlocutores moradores de Corumbá é "aqui não tem preconceito".

Isso, porém, não se confirmou na etnografia on-line, como, por exemplo, nos comentários destacados no fragmento de um diálogo na sala que transcrevemos abaixo:

\section{$[\ldots]$}

(09:22:19) carinhosorj fala para nayara: so viadao nessa porra

(09:22:39) carinhosorj fala para nayara: esses corumbaenses ${ }^{16}$ nao perdem a mania de dar o $\mathrm{cu}$

(09:22:42) junior entra na sala...

(09:22:42) NEGRO DOTADO ${ }^{17}$ entra na sala...

(09:22:47) carinhosorj ${ }^{18}$ fala para nayara: cambada de arrombado

(09:23:03) carinhosorj fala para nayara: por isso que eu como a mulher de vcs

(09:23:10) Amala fala para Todos: Ta procurando uma massagem relaxante?! ..

AcompanhantesMS.com.br

(09:23:14) carinhosorj fala para nayara: seus boiolas

(09:23:24) junior (reservadamente) fala para Todos: alguem afim de xupa um pau agora?

(09:23:28) raphael sai da sala...

(09:23:36) carinhosorj fala para nayara: foi mal nayara

(09:23:45) cachorra q macho ${ }^{19}$ entra na sala...

(09:23:49) carinhosorj fala para nayara: tem uns caras me enchendo o saco aqui

(09:23:50) Tarado $^{20}$ entra na sala...

(09:23:59) carinhosorj fala para nayara: e eu digitei na janela errada

(09:24:08) carinhosorj fala para nayara: mil desculpas

(Sexta-feira, 02-10-2015, horário de entrada na sala às 20:56-grifos nossos)

Além do forte teor sexual dos apelidos ou mensagens de texto presentes no fragmento, chamamos a atenção para o fato de o usuário "carinhosorj" se direcionar a "nayara", acidentalmente em modo "público", direcionando repetidas ofensas aos usuários que buscavam sexo com outros homens, apresentando não querer ser "incomodado" com flertadas. Sobre esse aspecto, nos chama a atenção o usuário "carinhosorj" afirmar que "por isso que eu como a mulher de vcs", dando a entender que os homens

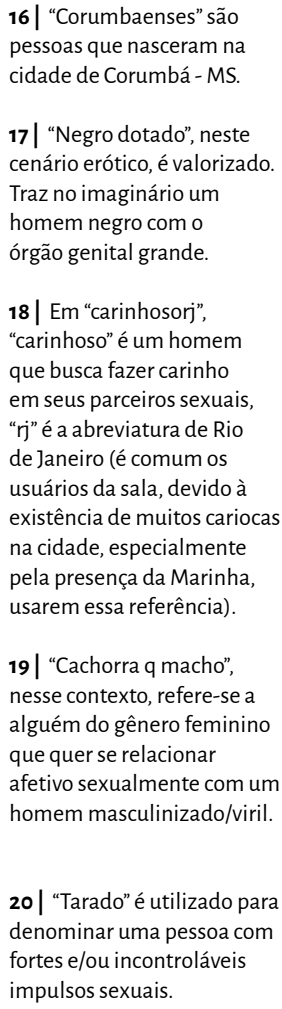

16 | "Corumbaenses" são pessoas que nasceram na cidade de Corumbá - MS.

17| "Negro dotado", neste cenário erótico, é valorizado. Traz no imaginário um homem negro com o órgão genital grande.

18 | Em "carinhosorj", "carinhoso" é um homem que busca fazer carinho em seus parceiros sexuais,

"ri" é a abreviatura de Rio de Janeiro (é comum os usuários da sala, devido à existência de muitos cariocas na cidade, especialmente pela presença da Marinha, usarem essa referência).

19| "Cachorra q macho", nesse contexto, refere-se a alguém do gênero feminino que quer se relacionar afetivo sexualmente com um homem masculinizado/viril.

20| "Tarado" é utilizado para denominar uma pessoa com fortes e/ou incontroláveis impulsos sexuais. 
que estão em busca de relações afetivo-sexuais com outros homens são casados com mulher. Outra característica do usuário é sua descrição "rj", que o caracteriza como sendo do Rio de Janeiro, o que fundamenta ainda mais o espaço da sala como sendo um local de buscas por encontros afetivo-sexuais, por quem está na região.

Em um estudo voltado a uma sala de bate-papo direcionada para o público masculino gay na cidade de São Paulo, Miskolci (2009) apresenta alguns dos motivos de se criar vínculos nestes sites on-line, sejam eles relações homoafetivas ou de amizades, que nos parece apropriado para pensar também a realidade fronteiriça aqui em discussão:

[...] a maioria jamais quis (ou pôde) se expor de forma a frequentar algum local claramente gay ou lésbico. Estes indivíduos, os quais, pelas razões as mais diversas (geográficas, econômicas, puro e simples preconceito), se consideram "fora do meio", encontraram na web uma forma de conhecer parceiros e até fazer amizades sem o ônus da exposição de seus interesses eróticos no espaço público. (Miskolci, 2009: 176).

Em contexto corumbaense, segundo o estudo com homens idosos com condutas homossexuais no pantanal sul-mato-grossense, Passamani (2018) corrobora essa mesma análise em relação a visibilidade off-line. Segundo esse autor, interessa a esses homens preocupar-se com como a visibilidade de determinada orientação sexual ou identidade de gênero será interpretada pelos outros e, além disso, o que pode decorrer desta interpretação, especialmente, no que diz respeito às formas de violência, preconceito e discriminação. Segundo ele, devido a isso, existe recorrentemente um "mapear" os corpos e condutas, o que faz com que os sujeitos controlem e administrem graus e estratégias de visibilidade conforme os locais nos quais estão circulando e interagindo.

Para melhor compreender o "controle" e "administração" de visibilidade em Corumbá, é preciso entender que a fofoca é um fenômeno onipresente no local, ela "faz parte do aprendizado social na cidade e é amplamente reconhecida como um fenômeno local de alta intensidade" (Costa, 2018: 403). Segundo Costa:

\footnotetext{
a fofoca não trata apenas de um juízo moral sobre uma conduta que não seja "correta" ou "normal", ou de um modelo moral dominante, mas principalmente o fofoqueiro busca atingir um fim, que pode ser a demissão de um rival, a remoção de uma pessoa da cidade, ou a separação de um casal, por exemplo, utilizando, para esse fim, uma "gramática" dos valores morais vigentes, para atingir a reputação pessoal. Assim, para alcançar um fim prático, a fofoca é utilizada como uma tática ou estratégia, que se utiliza dos padrões normalizadores e morais vigentes para atingir determinadas pessoas ou grupos (Idem: 415-416).
}

Isso corrobora o fato de que o uso de meios on-line, como as redes sociais e as próprias salas de bate-papo, são maneiras de possibilitar trânsitos mais "seguros" desses 
usuários; uma forma estratégica de autoproteção, o que pode ser lido como uma questão problematizadora da ideia de que, nas relações off-line, não existem preconceitos na cidade quando o assunto é gênero dissidente e/ou sexualidade disparatada.

Rubin (1984), ainda que em relação a outro período e contexto histórico, já afirmou o quanto a "sexualidade dissidente" é mais rara e, ao mesmo tempo, vigiada mais de perto nas pequenas cidades ou áreas rurais, quando comparadas com grandes centros. Nesse estudo, ainda que possamos entender Corumbá como uma cidade "do interior" do estado de Mato Grosso do Sul, encontramos uma interação intensa (vide a fronteira e o turismo de pesca) que nos permite pensar o quanto ela se diferencia de outras cidades "interioranas". Mais especificamente, há de se pensar no quanto ser fronteiriça marca essas relações.

A frase "lá não tem gay ${ }^{21 "}$, dirigida às cidades fronteiriças do lado boliviano, é muito recorrente entre muitos gays, travestis e transexuais, ou homens efeminados que vivem em Corumbá, e pode, junto com a frase "aqui não tem preconceito", ser vista igualmente como um mecanismo de produção de diferenças em termos de nacionalidade. É como se a fronteira tivesse apenas o lado do "Outro" elá fosse diferente "daqui" em termos de se viver sem preconceitos em torno dos gêneros dissidentes e das sexualidades disparatadas. Há, portanto, certa invisibilidade "estratégica" que caracteriza parte do discurso sobre o "Outro". Utilizamos "estratégica" aqui no sentido do que esta invisibilidade possibilita, nos termos da produção de diferenças, não necessariamente consciente e calculada, mas como altamente produtora de significados nos contextos das relações de poder local.

A visibilidade gay em Corumbá é grande, por exemplo, devido às lideranças presentes na produção dos desfiles das escolas de samba no carnaval, nas apresentações de bandas e fanfarras das escolas públicas e privadas, nas festas juninas e suas quadrilhas muito bem coreografadas, nas apresentações de dança e concursos de Miss Gay e Musa Gay do Carnaval. Todos esses eventos colocam a cidade em destaque valorativo no estado. Essa visibilidade, contudo, não parece ameaçar a "cultura heterossexual" - onde "um conjunto de práticas sexuais se confunde com a trama amorosa da intimidade e com os valores familiares que constitui de significação profunda e visível o pertencimento à sociedade" (Berlant e Warner, 2002: 237). Um sinal disso é a própria sala de bate-papo ser tão frequentemente e majoritariamente frequentada por homens em busca de relações afetivo sexuais com outros homens sob "discrição" e "segredo", como já discutido aqui.

No que se refere à avaliação de que não há gays do outro lado da fronteira, tanto a etnografia on-line como a off-line, mostrou que não é bem assim. Segundo o que pudemos observar, parte dos usuários que eram de outras localizações que não Corumbá, usavam na descrição do apelido o lugar de onde eram, por exemplo,

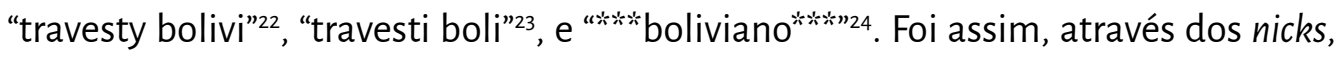
que pudemos identificar usuárias da Bolívia, porém, somente pelo apelido não é

\author{
21 Gay, segundo o que \\ pudemos observar, tanto \\ on-line como off-line, é uma \\ categoria êmica que, de \\ forma generalizada, refere-se \\ a um conjunto variado de \\ experiências identitárias, \\ englobando, entre outras, as \\ de travestis e transexuais.
}

22 | "Travesty bolivi" é uma usuária que se identifica com o gênero feminino, mas ao nascer foi designada pelo "sexo" masculino, $\mathrm{e}$ que mora na Bolívia.

23| "Travesti boli" tem o mesmo significado que a usuária "Travesty bolivi".

24 | "boliviano" é um homem que nasceu na Bolívia. 
possível afirmar de qual cidade elas são. Na experiência etnográfica off-line também pudemos encontrar gays e travestis que moravam nas cidades fronteiriças do lado boliviano e mantinham contatos com brasileiros em Corumbá, inclusive afetivo-sexuais, muitos sob "segredo".

Contudo, mesmo se tratando de lugares próximos, onde o município de Corumbá se caracteriza como um polo de atração para os/as moradores/as dos municípios bolivianos vizinhos, a quantidade de usuários/as da Bolívia na sala, assim identificados/as, que encontramos, é muito pequena. "Publicamente", mesmo estando na sala, não pode ser observado diálogos "públicos" entre eles/as e outros/as usuários/as. Acreditamos que seja pelo problemático senso comum sobre as cidades fronteiriças e por alguns preconceitos por parte da população corumbaense, conforme caracterizado por Costa:

\footnotetext{
A presença dos bolivianos em Corumbá é vista como um "problema social", sobretudo por parte da elite local, mas com um preconceito difuso por outros setores da sociedade, $\mathrm{e}$ existe, no discurso e na prática, a reprodução de preconceitos e de uma estigmatização em relação aos bolivianos e seus descendentes. Esses conflitos que emergem na região revelam processos de exclusão e de construção social de estigmas sociais, que são reforçados pela imagem negativa do senso comum, referida à fronteira como área de tráfico de drogas e de armas, de contrabando e falsificação de produtos. (2013a: 144).
}

Sabe-se que, comumente, muitos brasileiros discriminam bolivianos, e esse tipo de relação acontece nas interações de diferentes ordens, tanto econômicas como mercadológicas (Costa, 2013b), mas, como mostra parte da etnografia realizada por este pesquisador fora da sala de bate-papo, isso também ocorre no campo do desejo afetivo-sexual, como negando a existência de gays nas cidades bolivianas que fazem fronteira com o Brasil na região de Corumbá e apontado que, diferente dos corumbaenses, eles são preconceituosos em termos de gênero e sexualidade. É bastante comum a avaliação de brasileiros que buscam sexo com homens de que eles, os bolivianos, não são belos e atraentes. Esse tipo de discriminação ocorre ainda que existam muitos casos, especialmente entre as pessoas de classe social tida como mais baixa, de casamentos e constituição de famílias heterossexuais entre pessoas dessas duas nacionalidades (Costa, 2013a; Esselin [et al], 2012).

Assim, podemos pensar que classificação hierárquica entre "bom sexo" (normal, natural, saudável, sagrado) e o "mau sexo" (anormal, não natural, doentio, pecaminoso), apontada por Gayle Rubin (1984), ainda é rentável para pensarmos as relações entre gêneros dissidentes e sexualidades disparatadas na contemporaneidade, contudo, a questão fronteiriça (aqui, em relação também ao espaço geográfico, e não exclusivamente simbólico), parece ser um fator contextualizador e de atualização de tal reflexão. Dito de outro modo, na região de Corumbá, além do 
"bom sexo" ser heterossexual, monogâmico, reprodutivo, entre gerações de idades próximas, é preciso também ser da mesma nacionalidade.

\section{CONSIDERAÇõES FINAIS}

Os resultados das análises apresentam o quanto a etnografia on-line é importante quando nos propomos a estudar as relações humanas mediadas socioculturalmente em tempos de internet. Ela nos mostra o quanto os ambientes on-line também são lugares discursivos e, neste caso, em certa medida, produzem efeitos de subjetivações nos grupos sociais que os observam e neles estão inseridos, em continuum com os espaços off-line, isto é, em consonância os espaços estão produzindo preconceitos e discriminações.

Vimos que a performance geracional é um marcador social da diferença que se destaca em usuários/as dentro do campo apresentado na etnografia on-line. Isto é, foi observado que há uma maior procura por pessoas que colocam seus nicknames no diminutivo e, geralmente, esta procura parte de nicknames no masculino, sobretudo quando o nick se expressa ser do gênero feminino. Dito de outra forma, quando a pesquisadora utilizou de apelidos que a descrevia no feminino e diminutivo, como quando usou "Carolzinha", a procura de usuários no masculino aumentaram.

No entanto, as salas de bate-papo Uol Corumbá, em termos eróticos, envolvem, principalmente, uma grande quantidade de usuários homens em busca de sexo com outros homens, se compararmos com a quantidade total de membros ocupantes dela nos diferentes dias e horários que pudemos observar. Esses usuários homens parecem buscar "segurança" e "proteção" do ambiente on-line para a interação; isso é um sinal de que a cidade tem, como características, preconceitos com experiências de pessoas com gêneros dissidentes e sexualidades disparatadas. Esse tipo de preconceito aparece em reações preconceituosas na sala, e pode ser um dado problematizador da percepção local de que a cidade não tem preconceito.

Além disso, encontramos travestis no bate-papo que são bolivianas. Isso, somado às experiências do campo off-line, que nos permitiu encontrar gays que moram do outro lado da fronteira, mostra que a frase "lá não tem gay" é, juntamente com a "aqui não tem preconceito", mecanismos de produção de um "Outro" desvalorizado. Afinal, a visibilidade gay em Corumbá é um diferencial valorativo não só em relação à Bolívia, como no contexto sul-mato-grossense. Em nada isso significa, contudo, que a "cultura heterossexual" esteja sendo ameaçada. Antes, apontam que as normas e convenções que envolvem a "discrição" daqueles que estão, de algum modo, não correspondendo à matriz de inteligibilidade de gênero, têm reforçado pertencimentos nacionais de experiências em contextos fronteiriços diante de um "Outro" desqualificado.

Neste contexto, pode-se concluir que o ambiente on-line proporciona diferentes possibilidades de os sujeitos vivenciarem as mesmas e/ou outras formas 
de experimentações do seu gênero e sexualidade. Assim como afirmaram Leitão e Comes (2018), as plataformas digitais podem ser vistas como laboratórios para novas experimentações de si. Essas experimentações como apresentadas durante o artigo estavam presentes nas tentativas de diálogo com a pesquisadora, através das escolhas dos "apelidos" dos usuários, ou mesmo pelas conversas enviadas ao "público" da sala. Essas expressões mostraram práticas não normativas do desejo, isto é, que transgride uma norma heteronormativa, evidente, principalmente, na procura de homens por sexo com outros homens.

Por fim, as salas de bate-papo não podem ser consideradas um "mundo à parte", pois as práticas sexuais, ou mesmo apenas os encontros, ocorrem em diversas regiões da cidade, em espaços off-line, isto é, a sala surge como um mediador dos desejos. Além disso, percebeu-se que uma cidade caracterizada diferentemente das cidades chamadas "globais", também está produzindo novas formas de comunicação, característica da modernização.

Carla Cristina de Souza é mestra em Antropologia Social pelo Programa de Pós Graduação em Antropologia Social da Universidade Federal de Mato Grosso do Sul (PPCAS/UFMS). Pesquisadora do Impróprias - Crupo de Pesquisa em Gênero, Sexualidade e Diferenças (UFMS/CNPq). Graduada em Ciências Sociais - Bacharelado (UFMS). Foi Bolsista Voluntária do PIBIC/CNPq (2015/2016). Técnica de Projetos na Organização da Sociedade Civil, Instituto Brasileiro de Inovações Pró Sociedade Saudável do Centro Oeste (IBISS-CO).

Tiago Duque é pós-doutor em Educação pela Universidade Federal do Rio Grande do Sul (UFRCS). Doutor em Ciências Sociais pela Universidade Estadual de Campinas (UNICAMP). Graduado em Ciências Sociais pela Pontifícia Universidade Católica de Campinas (PUC-Campinas). Professor da Universidade Federal de Mato Grosso do Sul (UFMS) no Programa de Pós-Graduação em Antropologia Social (PPCAS) e do Programa de Pós-Graduação em Educação do Campus do Pantanal (PPCE-CPAN). Pesquisadordo Impróprias-Crupo de Pesquisa em Cênero, Sexualidade e Diferenças (UFMS/CNPq).

\section{CONTRIBUIÇÃO DE AUTORIA:}

Carla Cristina de Souza contribuiu para concepção e análise de dados, redação, discussão de resultados, realização do campo etnográfico on-line e revisão do artigo. Tiago Duque contribuiu para concepção e análise de dados, redação, discussão de resultados, realização do campo etnográfico off-line e revisão do artigo. 


\section{REFERÊNCIAS BIBLIOCRÁFICAS}

AMARAL, Adriana; NATAL, Geórgia; VIANA, Lucina. 2008. "Netnografia como Aporte Metodológico da Pesquisa em Comunicação Digital". Revista Sessões do Imaginário, v.2, n.20:34-40.

BANDUCCI JÚNIOR, Álvaro. 2012. “O Pantanal e a sua gente: diversidade étnica e cultura". In: MORETTI, Edvaldo Cesar; BANDUCCI JUNIOR, Álvaro (Orgs). Pantanal: territorialidades, culturas e diversidade. Campo Grande: Ed. UFMS: 09-23.

BELELI, lara. 2015. "O imperativo das imagens: construção de afinidades nas mídias digitais". Cadernos Pagu, n.44: 91-114.

BENTO, Berenice. 2011. "Política da Diferença: Femininos e Transexualidades". In: COLLING, Leandro (org). Stonewall $40+$ o que no Brasil?, Salvador: 79-110.

BERLANT, Laurent \& WARNER, Michael. 2002. "Sexo em Público". In: JIMÉNEZ, Rafael M. M. (editor) Sexualidades transgressoras. Barcelona, Içaria: 229-257.

BUTLER, Judith. [1990] 2003. Problemas de gênero: feminismo e subversão da realidade. Rio de Janeiro, Civilização Brasileira.

BRAGA, Gibran Teixeira. 2015. "Não estou cobrando o que eu não posso dar: masculinidade simétrica no homoerotismo virtual". Sexualidad, Salud y Sociedad, v.21: 225-261.

CARRARA, Sérgio; FRANÇA, Isadora Lins; SIMÕES, Júlio Assis. 2018. "Conhecimento e práticas científicas na esfera pública: antropologia, gênero e sexualidade". Revista de Antropologia, v.61, n.1: 71-82.
COSTA, Gustavo Villela Lima da. 2018.

"'Diz que em corumbá tem muita conversa fiada': fofoca, política e moralidade em uma cidade do Pantanal". Política ESociedade, v.17, n.39: 396-426. . 2013a "O Muro Invisível: a nacionalidade como discurso reificado na fronteira Brasil- Bolívia". Tempo Social, v.25: 141-156. . 2013b "A Feira Bras-Bol em Corumbá (MS): notas sobre o comércio informal na fronteira Brasil-Bolívia". Contemporânea-Revista de Sociologia da UFSCar, v.3, n.2: 467-489.

DUQUE, Tiago. 2011. Montagens e desmontagens: desejo, estigma e vergonha entre travestis adolescentes. São Paulo: Annablume.

ESSELIN, Paulo Marcos; OLIVEIRA, Tito Carlos Machado de; OLIVEIRA, Marco Aurélio Machado de. 2012. Fronteiras esquecidas: a construção da hegemonia nas fronteiras entre os Rios Paraguai e Paraná. Dourados: Editora da UFCD.

FOUCAULT, Michel. [1976] 2007.

História da sexualidade I: A vontade de saber. Rio de Janeiro, Edições Graal.

KOZINETS, Robert V. 2014. Netnografia: realizando pesquisa etnográfica online. Porto Alegre, Penso.

LEITÃO, Débora K; COMES, Laura Graziela. 2017. "Etnografia em ambientes digitais: perambulações, acompanhamentos e imersões". Revista Antropolítica, n.42: 41-65. . 2018 "Gênero, sexualidade e experimentação de si em plataformas digitais on-line". Civitas-Revista de Ciências Sociais, v.18, n.1: 171-186. 
MACNANI, José Guilherme Cantor et al. 2002. "De perto e de dentro: notas para uma etnografia urbana". Revista Brasileira de Ciências Sociais, v.17, n.49: 11-29.

MILLER, Daniel. [2010] 2013. Trecos, Troços e Coisas: estudos antropológicos sobre a cultura material. Rio de Janeiro: Zahar.

MISKOLCl, Richard. 2017. Desejos Digitais: uma análise sociológica da busca por parceiros on-line. Belo Horizonte: Autêntica Editora. . 2012. "A gramática do armário: notas sobre segredos e mentiras em relações homoeróticas masculinas mediadas digitalmente", XXX International Congress of LASA, San Francisco. LASA 2012 Congress Paper Archive. Pittsburgh: LASA, v.1: 1-25. 2011. "Novas Conexões: notas teórico-metodológicas para pesquisas sobre o uso de mídias digitais". Cronos, v.12: 9-22. . 2009. "O Armário Ampliado: notas sobre sociabilidade homoerótica na era da internet". Cênero, v.9: 171-190.

NOVELI, Marcio. 2010. “Do off-line para o online: a netnografia como um método de pesquisa ou o que pode acontecer quando tentamos levar a etnografia para a Internet?" Metodista, v. 12, n.6: 107-133.
OLIVEIRA, Marco Aurélio Machado de; CAMPOS, Davi Lopes. 2012. "Migrantes e fronteira: lógicas subversivas, vidas referidas". In: PEREIRA, Jacira Helena do Valle; OLIVEIRA, Marco Aurélio Machado de (orgs.). Migração e integração: resultados de pesquisa em Mato Grosso do Sul. Dourados: Editora UFCD: 17-37.

PASSAMANI, Guilherme Rodrigues. 2018. Batalha de Confete: envelhecimento, condutas homossexuais e regime de visibilidade no pantanal-MS. Rio de Janeiro: Papéis Selvagens.

PERLONGHER, Néstor. 2008. O negócio do michê: prostituição viril em São Paulo. São Paulo: Fundação Perseu Abramo.

PISCITELLI, Adriana. 2008.

"Internseccionalidades, categorias de articulação e experiências de migrantes brasileiras". Sociedade e Cultura, v.11, n.2: 263-274.

RUBIN, Gayle. 1984. “Thinking Sex: Notes for a Radical Theory of the Politics of Sexuality". In: VANCE, Carol. Pleasure y danger: exploring female sexuality: 267-319.

RAMOS, Jair de Souza. 2015. "Subjetivação e poder no ciberespaço. Da experimentação à convergência identitária na era das redes sociais". Vivência: Revista de Antropologia, v.1, n.45: 57-75.

Recebido em 16 de outubro de 2018. Aceito em 16 de dezembro de 2019. 